\section{Os múltiplos sentidos da categoria "empowerment" no projeto de Promoção à Saúde}

\author{
The multiple meanings of "empowerment" \\ in the health promotion proposal
}

Sérgio Resende Carvalho 1

\section{Introdução}

Starting with a review of the literature and documents pertaining to health promotion in the developed countries, highlighting the Canadian output, the author reflects on the multiple meanings ascribed to the "empowerment" category/strategy. After a summary of the conceptual development of health promotion ideals, the paper analyzes the theoretical aspects of "empowerment", suggesting its classification into two main approaches: psychological and community-based. The author contends that community "empowerment" helps define health promotion as a proposal aimed at transforming the status quo and the production of healthy subjects. The paper concludes by exploring the potential contributions of social/community "empowerment" to health education practices and reorganization of the Brazilian National Health System (SUS).

Public Health; Health Promotion; Health Education
Perante as mudanças sociais, políticas e culturais, o esgotamento do paradigma biomédico e a mudança do perfil epidemiológico desenvolve-se, nas últimas décadas, o projeto da Promoção à Saúde enquanto uma resposta aos desafios sanitários contemporâneos. Surgida nos países desenvolvidos, nos anos 70, esta proposta assume o status de uma das principais linhas de atuação da Organização Mundial da Saúde influenciando, nos anos seguintes, a elaboração de políticas de saúde de diversos países.

No Brasil, este ideário tem sido objeto de interesse de inúmeros estudiosos e dirigentes do setor saúde. Seus princípios e diretrizes influenciam a elaboração do arcabouço teórico do modelo de Vigilância à Saúde, sustenta a proposta de Cidades Saudáveis, subsidia práticas de Educação à Saúde e se faz presente junto a projetos de reorganização da rede básica que vêm, nos últimos anos, se desenvolvendo sob o manto do Programa Saúde da Família 1,2,3,4.

Partindo do pressuposto de que o conceito/estratégia de "empowerment" constitui um eixo central da Promoção à Saúde, procuro neste trabalho clarificar esta terminologia e demonstrar a importância desta estratégia para o mencionado ideário.

Realizei, para isto, uma investigação em que utilizei como fontes a produção relevante de autores anglo-saxões das áreas da Saúde Públi- 
ca e Ciências Sociais, documentos institucionais e anotações pessoais de seminários, aulas e entrevistas realizadas durante estágio realizado junto ao Departamento de Ciências Sociais da Universidade de Toronto, no Canadá 5.

Após uma breve síntese sobre o desenvolvimento conceitual do ideário da Promoção à Saúde, este ensaio analisa em profundidade aspectos teóricos da categoria "empowerment", buscando refletir sobre os seus múltiplos sentidos e conseqüências para um projeto de saúde que tenha compromisso com a transformação do status quo e a produção dos sujeitos e da saúde. Concluo este trabalho sugerindo elementos e questões que julgo pertinentes para a consolidação dos princípios e diretrizes do Sistema Único de Saúde (SUS).

\section{O Relatório Lalonde e a vertente behaviorista da Promoção à Saúde nos anos 70}

A Promoção à Saúde moderna tem como documento de referência o Relatório Lalonde, publicado em 1974. Esse documento, um memorando de discussão produzido pelo Ministério de Bem Estar e Saúde do Canadá, sintetizou um ideário que preconiza como eixo central de intervenção um conjunto de ações que procuram intervir positivamente sobre comportamentos individuais não-saudáveis.

Esse documento procura elaborar um arcabouço conceitual sobre a saúde que fosse intelectualmente aceitável e suficientemente simples para permitir uma rápida localização perante qualquer idéia, problema ou atividade relacionada à saúde: uma espécie de mapa do território da saúde. O resultado concretiza-se na produção de um modelo que inter-relaciona quatro grupos explicativos do fenômeno saúde/doença: ambiente (natural e social), estilo de vida (comportamento individual que afeta a saúde), biologia humana (genética e função humana) e organização dos serviços de saúde 6 .

Partindo do pressuposto de que práticas pouco saudáveis são "riscos auto-impostos" e causas relevantes da não-saúde, afirma-se a necessidade de uma nova agenda de intervenção que lograsse interferir sobre os hábitos de vida. Essas estratégias, centrais às práticas de Promoção à Saúde até os dias atuais, têm tido efeitos positivos no que se refere à adoção de estilos de vida mais saudáveis de determinados grupos sociais, porém, no seu conjunto, vêm obtendo impacto limitado sobre as condições de vida da população marginalizada, resultado que alguns investigadores explicam, pela ênfase unilateral em intervenções sobre estilos de vida às custas de um enfoque ampliado sobre as causas sociais da não-saúde 7 .

Esta constatação irá fazer com que, nos anos 80 , autores como Labonte \& Penfold 8 venham a público para alertar que a perspectiva behaviorista de Promoção à Saúde, ao escamotear as mazelas e estruturas sociais causadoras da não-saúde, poderia servir de anteparo à implementação de políticas neoliberais socialmente restritivas, culpabilizando, no processo, as vítimas ("blaming the victims") da iniqüidade social.

\section{A Carta de Ottawa e o ideário Nova Promoção à Saúde}

Limites teóricos e práticos da abordagem behaviorista estimulam o surgimento, nos anos 80, de uma perspectiva socioambiental. Esta corrente, que aqui denomino como "Nova Promoção à Saúde" visando a diferenciá-la da que lhe antecedeu, introduziu novas idéias, linguagens e conceitos sobre o que é saúde e apontou novos caminhos para a produção da saúde.

Este ideário está detalhado em inúmeros documentos institucionais merecendo destaque, entre outros, o memorando de trabalho disseminado pelo Escritório Europeu de Promoção à Saúde em 1984, que sintetiza pela primeira vez as grandes linhas de ação da Nova Promoção à Saúde 9 e a Carta de Ottawa produzida durante a 1ạ Conferência Internacional de Promoção à Saúde, realizada no Canadá no ano de 1986 (http://www.who.int/hpr/docs/ ottawa.html, acessado em 16/Mar/2004).

Em linha de continuidade com Alma Ata (http://www.who.dk/policy/almaata.htm, acessado em 16/Mar/2004) esta corrente considera que a justiça social, a eqüidade, a educação, o saneamento, a paz, a habitação, o salário digno, a estabilidade do ecossistema e a sustentabilidade dos recursos naturais são pré-requisitos essenciais à saúde da população. Recomenda como eixos de suas estratégias e ações: (a) a constituição de políticas públicas saudáveis; (b) a criação de ambientes sustentáveis; (c) a reorientação dos serviços de saúde; (d) o desenvolvimento da capacidade dos sujeitos individuais e (e) o fortalecimento de ações comunitárias. 
Um dos núcleos filosóficos dessa abordagem é o conceito de "empowerment" presente, implícita ou explicitamente, no interior das premissas e estratégias mencionadas. Esta categoria corporifica a razão de ser da Promoção à Saúde enquanto um processo que procura possibilitar que indivíduos e coletivos aumentem o controle sobre os determinantes da saúde para, desta maneira, terem uma melhor saúde 10.

No que se segue, descrevo, analiso e reflito os diversos significados da categoria "empowerment" buscando, posteriormente, discutir seus aportes e suas limitações para se pensar um projeto sanitário comprometido com a mudança e produção de sujeitos e da saúde.

\section{O "empowerment" e seus múltiplos sentidos}

“Empowerment" é um conceito complexo que toma emprestado noções de distintos campos de conhecimento. É uma idéia que tem raízes nas lutas pelos direitos civis, no movimento feminista e na ideologia da "ação social" presentes nas sociedades dos países desenvolvidos na segunda metade do século XX. Nos anos 70, este conceito é influenciado pelos movimentos de auto-ajuda, e, nos 80 , pela psicologia comunitária. Na década de 90 recebe o influxo de movimentos que buscam afirmar o direito da cidadania sobre distintas esferas da vida social entre as quais a prática médica, a educação em saúde e o ambiente físico.

No artigo intitulado Empowerment: o Cálice Sagrado da Promoção à Saúde?, Christopher Rissel 11 reconhece os potenciais aportes desta categoria para a promoção à saúde; alertando, não obstante, a necessidade de alguma precaução antes que esta noção seja abraçada entusiasticamente como uma raison d'être desse ideário. Entende, esse autor, que a carência de um embasamento teórico consistente e as múltiplas interpretações sobre essa noção na literatura são elementos que dificultam a utilização desse conceito no campo da saúde, o que demanda um pensamento crítico, que adjetive e esclareça o significado do mesmo.

Essa dificuldade está refletida no modo com que esta categoria vem sendo traduzida em textos nos idiomas português e espanhol: para alguns é sinônimo de "empoderamento", "apoderamento" e, para outros, de "emancipación” 12. Significados distintos, uma vez que "apoderar" é sinônimo de dar posse, "domínio de”, "apossar-se", “assenhorear-se”, "dominar”, "conquistar", “tomar posse”. São definições que diferem do verbo "emancipar”, que significa, por sua vez, "tornar livre, independente" 13. A inexistência do termo "empoderamento" na língua portuguesa e a diversidade de sentidos do termo "apoderamento", ilustram a dificuldade de realizar a tradução fidedigna de "empowerment" para o nosso idioma. Opto, por estas razões, por utilizar no estudo em questão o termo "empowerment".

Para explicitar este conceito é preciso buscar a resposta para algumas questões: o que está por trás da categoria “empowerment"? Qual a teoria sobre o poder que sustenta este conceito? Processos de "empowerment" devem voltar-se para mudança individuais ou coletivas? É possível um processo de "empowerment" que não questione as estruturas existentes? Qual a relação entre o sentimento de poder e o poder sobre os recursos concretos? Qual a conseqüência do "empowerment" para as relações internas às equipes de saúde e entre profissionais e usuários dos serviços? Qual a relação entre "empowerment" e comunidade? A quem servem o "empowerment" e a participação comunitária? Variações nas respostas dadas a estas perguntas irão determinar distintos significados do conceito de "empowerment".

A seguir reflito sobre estas questões ao descrever, e comentar, duas noções distintas sobre a categoria "empowerment" - a psicológica e a comunitária - que se fazem presentes em distintas interpretações do ideário da Promoção à Saúde.

\section{O "empowerment" psicológico e a Promoção à Saúde}

Podemos definir o "empowerment" psicológico como um sentimento de maior controle sobre a própria vida que os indivíduos experimentam através do pertencimento a distintos grupos, e que pode ocorrer sem que haja necessidade de que as pessoas participem de ações políticas coletivas. Influenciando esta formulação encontramos uma perspectiva filosófica individualista que tende a ignorar a influência dos fatores sociais e estruturais; uma visão que fragmenta a condição humana no momento em que desconecta, artificialmente, o comportamento dos homens do contexto sociopolítico em que eles encontram-se inseridos.

Esta postura leva, segundo Riger 14 (p. 280), à formulação de uma imagem do indivíduo "empowered" (com poder) como sendo aquele que é "comedido, independente e autoconfiante, capaz de comportar-se de uma determinada maneira e de influenciar o seu meio e atuar de acordo com abstratos princípios de justiça e de 
equilíbrio" 14. Deste arcabouço deriva a formulação de estratégias de promoção que têm como objetivo fortalecer a auto-estima e a capacidade de adaptação ao meio e o desenvolvimento de mecanismos de auto-ajuda e de solidariedade.

Entre essas encontram-se práticas educativas que buscam contribuir para a formação da "consciência sanitária" por meio de um esforço pedagógico sistemático e permanente, que envolve técnicas focais e de marketing social e que tem como objetivo finalístico a manutenção da harmonia social e de uma relação saudável entre indivíduo com o seu meio externo.

Weissberg 15 caracterizou esta perspectiva como uma espécie de "cogito empowerment, ergo sum empowered"; o sentimento de poder criando a ilusão de sua existência efetiva de poder por parte dos indivíduos, no momento em que a maior parte da vida é controlada por políticas e práticas macrossociais. O que está em questão não é o poder real, mas sim, o "senso de empowerment" levando à personalização da política que pode favorecer a manutenção do status quo. "A experiência do indivíduo em relação ao poder, ou à falta deste, pode não ter relação com a capacidade real de influência, $e$ um aumento do sentido de empowerment nem sempre reflete um aumento do poder real. (...) Isto não significa que o indivíduo não possa ter nenhuma influência ou que suas percepções individuais não sejam importantes, mas, antes, significa que reduzir o poder à psicologia individual é ignorar o contexto político e histórico em que as pessoas atuam. Confundir a habilidade real de alguém em controlar as coisas com um sentido de empowerment despolitiza este último" 14 (p. 292).

Esta concepção de "empowerment" nem sempre incide sobre a distribuição de poder e de recursos na sociedade e pode constituir-se em mecanismo de regulação social. Declarações de princípios contra a iniqüidade social, a favor de uma sociedade saudável e socialmente justa, e que preconizam o "empowerment" de indivíduos e coletivos podem transformarse em discursos vazios no momento em que não se discute as raízes dos problemas nem se busca apontar alternativas ao status quo. Por meio destes artifícios, governos e instituições conservadoras podem legitimar suas práticas neutralizando, de passagem, proposições que questionam a ordem social.

Isso vem permitindo que, embora expresso na linguagem que afirma importância da autonomia das pessoas e da diminuição da dependência de instituições macrossociais, o "empowerment" psicológico venha sendo usado para justificar a diminuição e o retrocesso na prestação de serviços sociais e de saúde em tempos de conservadorismo fiscal. Nos Estados Unidos, por exemplo, políticas de corte neoliberal vêm combinando a noção de "empowerment" com a ideologia política da responsabilidade pessoal para sugerir que as pessoas façam, cada vez mais, uso de seus recursos próprios e/ou da comunidade antes de recorrer à ajuda de instituições estatais 16.

Essas críticas e constatações ensejam a elaboração de uma outra abordagem sobre o "empowerment”, que será objeto de descrição e análise no que se segue.

\section{O "empowerment comunitário" e a Promoção à Saúde}

Tomando como referência a produção de autores como Julian Rappaport, importante teórico do movimento da psicologia comunitária, Paulo Freire, educador brasileiro, e Saul Alinsky, ativista social norte-americano, estudiosos anglo-saxônicos vêm propondo a noção alternativa de "empowerment" comunitário como um elemento-chave de politização das estratégias da Nova Promoção à Saúde.

No processo de ressignificação e repolitização do sentido do "empowerment", esta abordagem trabalha com a noção de poder enquanto um recurso, material e não-material, distribuído de forma desigual na sociedade, como uma categoria conflitiva na qual convivem dimensões produtivas, potencialmente criativas e instituintes, com elementos de conservação do status quo. Para os teóricos do "empowerment" comunitário, a sociedade é constituída de diferentes grupos de interesses que possuem níveis diferenciados de poder e de controle sobre os recursos, fazendo com que processos de "empowerment" impliquem, muitas vezes, a redistribuição de poder e a resistência daqueles que o perdem.

Este entendimento tem conseqüências práticas subsidiando, por exemplo, a afirmação de que um projeto de transformação demanda, mais do que discursos vazios contra a pobreza, uma postura ativa de enfrentamento das determinações macro e microssociais da iniqüidade social, colocando em questão diferenciais de poder porventura existentes na relação entre especialistas e não-especialistas, entre populações de países ricos e desenvolvidos e de países pobres, entre homens e mulheres, e entre heterossexuais e homossexuais.

O afirmado anteriormente permite-nos definir, em termos genéricos, o "empowerment" 
comunitário como um processo, e um resultado, de ações que afetam a distribuição do poder levando a um acúmulo, ou desacúmulo de poder ("disempowerment") no âmbito das esferas pessoais, intersubjetivas e políticas. Nesta categoria encontram-se inscritos elementos que caracterizam um patamar elevado de "empowerment" psicológico, a participação ativa na ação política e a conquista de (ou possibilidade de) recursos materiais ou de poder por parte de indivíduos e coletivos 11 .

No processo de "empowerment" comunitário observa-se a presença de fatores situados em distintas esferas da vida social. Estão presentes microfatores encontráveis no plano individual, a exemplo do desenvolvimento da autoconfiança e da auto-estima; na mesosfera social encontramos estruturas de mediação nas quais os membros de um coletivo compartilham conhecimentos e ampliam a sua consciência crítica; ao nível macro de fatores há estruturas sociais como o estado e a macroeconomia.

Este entendimento permite afirmar que o poder convive, a todo o momento e ao mesmo tempo, sob o influxo dos macro e microdeterminantes presentes na vida em sociedade. Não é possível pensar, por exemplo, em processos de "empowerment" comunitário sem levar em conta as demais instâncias de funcionamento da vida em sociedade, entre as quais: a intrapsíquica, a intersubjetiva, a familiar, a comunitária, a étnico-cultural. Pensar esta categoria como um continuum que ocorre desde o nível do individual ao macro, passando pela de intermediação de coletivos e grupamentos sociais, conforme sugerido por Labonte 17 e Rissel 11, parece-me um maneira produtiva de se pensar as práticas de saúde em uma perspectiva integral.

$\mathrm{O}$ "empowerment" comunitário inclui, portanto, a experiência subjetiva do "empowerment" psicológico e a realidade objetiva de condições estruturais que são modificadas no momento em que ocorre a redistribuição de recursos. O "empowerment comunitário" demanda, por conseguinte, a convivência da noção de determinismo social com a de agenciamento humano 11,18 e o reconhecimento da mútua relação de condicionamento e determinação entre as macroestruturas e a ação de sujeitos individuais e coletivos.

Esta categoria requer, por conseguinte, uma prática que responda, simultaneamente à experiência subjetiva da "falta de poder" e que, ao mesmo tempo, contribua para a mudança das condições sócio-culturais. Ilustrando este fato na saúde é possível constatar que, se por um lado, muitos estudos epidemiológicos de- monstram o papel freqüentemente profundo da miséria e de outros fatores sociais, econômicos e políticos na determinação do estado da saúde do indivíduo, outros estudos demonstram que indivíduos são capazes de reconfigurar o contexto social no qual vivem e que isto tem conseqüências positivas para a saúde.

Essas observações são importantes para lembrar-nos de que devemos cuidar para que, em nome da luta contra a "tirania do indivíduo”, presente nos modelos teóricos biomédicos e da Promoção à Saúde behaviorista, não se corra o risco de criarmos uma formulação que induza à "tirania do coletivo". Este alerta deve-se ao fato de que muitas leituras da Promoção à Saúde tendem a moldar uma noção de "empowerment" que o reduz unicamente a ações políticas coletivas negando, portanto, o caráter multidimensional do poder. Embora o desenvolvimento crítico dos indivíduos não seja suficiente para a transformação da sociedade, ele é absolutamente necessário para que ela ocorra, uma vez que o envolvimento em processos de mudança demanda um mínimo de percepção do poder individual que sustente um processo produtivo de convivência nos espaços coletivos 16 .

A politização da saúde e de estratégias de promoção não significa que apenas a ação política direta é que tem validade. Quer dizer, isto sim, que devemos sempre "enquadrar os problemas de saúde e sua solução no seu contexto social, político e econômico" 16 (p. 302). O “empowerment" pode dar-se tanto em nível do coletivo quanto da relação intersubjetiva, podendo ocorrer em distintos espaços da ação sanitária, sejam eles o de promoção, de prevenção, de cura e/ou de reabilitação.

Considero que um aspecto central do " $\mathrm{em}$ powerment" comunitário seja a possibilidade de que indivíduos e coletivos venham a desenvolver competências para participar da vida em sociedade, o que inclui habilidades, mas também um pensamento reflexivo que qualifique a ação política.

Entendo que esta noção demanda mais do que o "controle sobre os determinantes da saúde", o "controle dos indivíduos sobre o próprio destino" 19. Ser dono do próprio destino é um processo, e uma condição, que demanda a aquisição de competências tais como o desenvolvimento da auto-estima e da confidência pessoal; a capacidade de analisar criticamente o meio social e político e o desenvolvimento de recursos individuais e coletivos para a ação social e política.

Mais do que repassar informações e induzir determinados comportamentos, o "empower- 
ment comunitário" deve buscar apoiar pessoas e coletivos a realizarem suas próprias análises para que tomem as decisões que considerem corretas, desenvolvendo a consciência crítica e a capacidade de intervenção sobre a realidade.

O "empowerment comunitário" pode ser considerado, portanto, como um processo de validação da experiência de terceiros e de legitimação de sua voz e, ao mesmo tempo, de remoção de barreiras que limitam a vida em sociedade. Indica processos que procuram promover a participação, visando ao aumento do controle sobre a vida por parte de indivíduos e comunidades, a eficácia política, uma maior justiça social e a melhoria da qualidade de vida.

\section{Considerações finais}

O estudo realizado conclui que "empowerment" é um conceito ambíguo, o que reforça achados de estudiosos da Promoção à Saúde quando afirmam, a exemplo de Stevenson \& Burke 20 (p. 54), que o discurso deste ideário sobre temas como a "prevenção de doenças, promoção à saúde, iatrogenia, 'empowerment' individual e coletivo, redes sociais, cuidados domiciliar è̀s famílias podem facilmente converter-se em justificativas ideológicas para a privatização e a desregulamentação dos serviços de saúde, com tudo o que isto implica para a qualidade e a eqüidade do cuidado podendo, ao mesmo tempo, representar um arcabouço teórico que suporta a progressiva transformação e democratização das políticas sociais".

Perante esta constatação, julgo de interesse nos perguntarmos: é possível estabelecer critérios que nos ajudem a identificar o sentido político e ideológico das estratégias e práticas de Promoção à Saúde? O estudo em questão mostra que sim, sustentando a pertinência de tomar-se, como parâmetro valorativo, o posicionamento da "Nova Promoção à Saúde" em relação ao compromisso com a produção de saúde e com a produção de sujeitos reflexivos, autônomos e socialmente solidários.

Para que isto ocorra é fundamental a ampliação das práticas democráticas no campo da saúde, sendo útil viabilizar estratégias que busquem garantir a participação de sujeitos na definição do seu modo de encaminhar a vida e que valorizem, no cotidiano do fazer saúde, o encontro entre profissionais e usuários e as lutas pela garantia dos direitos da cidadania.

O conceito/estratégia do "empowerment" comunitário contribui para a consecução dos objetivos apontados, sendo-nos útil para repensarmos práticas de educação para a saúde, de gestão de organizações, de reorganização do processo de trabalho em saúde e estratégias de participação comunitária.

A título de exemplo, finalizo este trabalho destacando duas dessas interfaces que julgo de especial relevância para a consolidação do SUS no Brasil.

\section{Contribuições do "empowerment comunitário" para a educação à saúde}

A implementação de práticas e processos que tenham como meta o "empowerment comunitário" demanda abordagens educativas que valorizem a criação de espaços públicos (rodas e grupos de discussão, colegiados, gestores etc.), que logrem promover a participação dos indivíduos e coletivos na identificação e na análise crítica de seus problemas, visando a elaboração de estratégias de ação que busquem a transformação do status quo.

Sob a influência de Paulo Freire, os teóricos do "empowerment comunitário" vêm preconizando a efetivação de um modelo pedagógico que assuma a "educação como uma prática da liberdade". Este projeto, que alguns denominam de "empowerment education" e que poderia ser igualmente denominado de "educação popular" e/ou "educação para a transformação" 19 , procura romper com métodos educativos centrados no exercício do "poder sobre" o outro, substituindo-o por métodos que valorizem o debate e a discussão de idéias, opiniões e conceitos com vistas à solução de problemas ("poder com").

$\mathrm{O}$ "empowerment education" busca, portanto, contribuir para a emancipação humana por meio do desenvolvimento do pensamento crítico e o estímulo a ações que tenham como objetivo realizar a superação das estruturas institucionais e ideológicas de opressão.

Esta perspectiva pedagógica, derivada do "empowerment comunitário", toma os indivíduos e grupos socialmente excluídos como cidadãos portadores de direitos e do "direito a ter direitos", distanciando-se do projeto behaviorista que tende a representar os marginalizados como pessoas dependentes que devem ser ajudadas, socializadas e treinadas. $\mathrm{O}$ "empowerment" transforma-se, neste contexto, em um ato político libertador que se contrapõe à concepção bancária de educação.

\section{"Empowerment comunitário"

e a reorganização dos serviços de saúde

A categoria "empowerment comunitário" pode, igualmente, contribuir para superar uma das 
grandes deficiências do movimento de Promoção à Saúde: a ausência de propostas consistentes de reorganização das práticas assistenciais.

Ela pode nos instrumentalizar, por exemplo, no delineamento de ações que tenham como objetivo a superação da desigualdade de poder que predomina na relação entre os profissionais e usuários. Sugere-se, aqui, trabalhar com uma noção de parceria entre profissionais, indivíduos e comunidades no lugar da relação hierárquica que confunde o trabalhador com o provedor de serviços e o usuário com o cliente. A incorporação do "empowerment comunitário” às práticas assistenciais demanda que novos modos de se fazer saúde, incorporem como diretriz, uma postura que encare os usuários na sua singularidade de sujeitos portadores de direito, em substituição a uma perspectiva que entende os usuários como suplicantes e beneficiários dos serviços.

Não caberia aqui a visão reducionista que idealizando o trabalho de profissionais, que atuam sobre o ambiente físico e social, subestimam o papel desempenhado por profissionais que prestam assistência clínica ao usuário. Esta é uma visão que encontra respaldo na produção de destacados investigadores da Promoção à Saúde, a exemplo de Labonte 17, no momento em que sustentam a importância dos serviços assistenciais como um espaço de realização do "empowerment", uma vez que instituições burocráticas e seus profissionais são passíveis de mudança.

Este entendimento concorre para o fortalecimento de uma perspectiva que afirma a necessidade de que, perante o esgarçamento do tecido social brasileiro, se valorize a rede de prestação de serviços do SUS, procurando ampliar o sentido de suas ações, visando a consolidá-lo enquanto espaço privilegiado de sociabilidade e politização de usuários, trabalhadores e gestores. Serviços de saúde que previnem a doença, que curam e que reabilitam devem, no Brasil, ter como objetivo contribuir para o aumento da capacidade reflexiva e de intervenção de diferentes sujeitos sobre o social. Ao contribuir para a constituição de cidadãos saudáveis, conscientes de seu direito e portadores do "direito a ter direitos", esses serviços aumentam a possibilidade de ações sociais que incidam positivamente sobre os múltiplos determinantes do processo saúde/doença.

\section{Resumo}

Partindo da revisão de literatura e documentos relevantes da Promoção à Saúde, procedentes de países desenvolvidos - com destaque para a produção canadense -, reflito sobre os múltiplos sentidos da categorialestratégia "empowerment". Após uma breve síntese sobre o desenvolvimento conceitual do ideário da Promoção à Saúde, o ensaio analisa em profundidade aspectos teóricos do "empowerment", sugerindo classificá-lo em dois enfoques principais: o psicológico e o comunitário. Considera que o "empowerment" comunitário contribui para definir a Promoção à Saúde enquanto um projeto voltado para a transformação do status quo e a produção de sujeitos saudáveis. Concluo o ensaio explorando potenciais contribuições do "empowerment" social/comunitário para as práticas de educação à saúde e para a reorganização da rede de serviços do Sistema Único de Saúde.

Saúde Pública; Promoção da Saúde; Educação em Saúde 


\section{Referências}

1. Buss PM. Promoção da saúde e qualidade de vida. Ciênc Saúde Coletiva 2000; 5:163-78.

2. Czeresnia D, Freitas CM. Promoção da saúde: conceitos, reflexões, tendência. Rio de Janeiro: Editora Fiocruz; 2003.

3. Teixeira CF, Paim J, Vilaboas A. SUS: modelos assistenciais e vigilância da saúde. Inf Epidemiol SUS 1998; 7:8-28.

4. Westphall MF. O movimento cidades/municípios saudáveis: um compromisso com a qualidade de vida. Ciênc Saúde Coletiva 2000; 5:39-52.

5. Carvalho SR. Saúde coletiva e promoção à saúde: uma reflexão sobre os temas do sujeito e da mudança [Tese de Doutorado]. Campinas: Faculdade de Medicina, Universidade Estadual de Campinas; 2002.

6. Lalonde M. A new perspective on the health of Canadians: a working document. Ottawa: Health and Welfare Canada; 1974.

7. Hyndman B. The evolution of health promotion. Health promotion in action: a review of effectiveness of health promotion strategies. Toronto: Centre for Health Promotion/ParticipACTION; 1998.

8. Labonte R, Penfold S. Canadian perspectives in health promotion: a critique. Health Educ 1981; 19:4-9.

9. World Health Organization. Health promotion: a discussion document on the concept and principles of health promotion. Health Promot 1984; 1:73-8.

10. World Health Organization. Glossary of health promotion terms. Geneva: World Health Organization/Division of Health Promotion, Educations and Communications/Health Education and Health Promotion Unit; 1998.
11. Rissel C. Empowerment: the holy grail of health promotion? Health Promot Int 1994; 9:39-47.

12. Zamudio MG. Teoría y guía práctica para la promoción de la salud. Montreal: Unité de Santé Internationale, Université Montreal; 1998.

13. Houaiss A, Villar MS. Dicionário Houaiss da língua portuguesa. 1a Ed. Rio de Janeiro: Editora Objetiva; 2001.

14. Riger S. What's wrong with empowerment. Am J Community Psychol 1993; 21:279-92.

15. Weissberg R. The politics of empowerment. Westport: Praeger Publishers; 1999.

16. Robertson A, Minkler M. New health promotion movement: a critical examination. Health Educ Q $1994 ; 21: 295-312$.

17. Labonte R. Health promotion and empowerment: practice frameworks. Toronto: Centre for Health Promotion/ParticipACTION; 1993.

18. Labonte R. Community empowerment: the need for political analysis. Can J Public Health 1989; 80:87-8.

19. Wallerstein N. Powerleness, empowerment, and health: implications for health promotion programs. Am J Health Promot 1992; 6:197-205.

20. Stevensohn HM, Burke M. Bureaucratic logic in new social movement clothing: the limits of health promotion research. Can J Public Health 1993; 83 Suppl 1:S47-53.

Apresentado em 16/Out/2003

Versão final reapresentada em 19/Abr/2004

Aprovado em 22/Abr/2004 